\title{
Análise do reforço têxtil produzido no Brasil para produção do concreto têxtil
}

\begin{tabular}{|c|}
\hline VINICIUS DE KAYSER ORTOLAN - DouTORANDO \\
\hline PEDRO HENRIQUE LEUCK - ENGENHARIA CIVIL \\
\hline MAIRA JANAINA OTT - Pesquisadora ITT Performance \\
\hline GIAN DE FRAGA MOREIRA - ACADÊMICO EM ENGENHARIA CIVIL \\
\hline $\begin{array}{l}\text { FERNANDA PACHECO - PROFESSOR } \\
\end{array}$ \\
\hline BERNARDO TUTIKIAN - PRoFESSOR \\
\hline
\end{tabular}

\section{RESUMO}

NESTE TRABALHO, O COMPORTAMENTO À TRAÇÃO DIRETA E À FLEXÃO DO CONCRETO TÊXTIL REFORÇADO COM TÊXTIL DE VIDRO AR PRODUZIDO NO BRASIL SÃO INVESTIGADOS DE FORMA EXPERIMENTAL. ENSAIOS DE TRAÇÃO DIRETA E FLEXÃO POR 4 PONTOS FORAM REALIZADOS EM 3 CORPOS DE PROVA REFORÇADOS COM DUAS CAMADAS DE TÊXTIL, POSICIONADOS COM AFASTAMENTO DE
3 MM DAS SUPERFÍ́CIES SUPERIOR E INFERIOR. O OBJETIVO DESTE ESTUDO É ANALISAR O POTENCIAL DE INSERÇÃO DO TÊXTIL DE VIDRO AR NACIONAL COMO ELEMENTO DE REFORÇO EM MATRIZ CIMENTÍCIA. OS RESULTADOS EXPERIMENTAIS DEMONSTRAM COMPORTAMENTO MECÂNICO SATISFATÓRIO AOS REQUISITOS QUE QUALIFICAM O CONCRETO TÊXTIL.

Palavras-chave: concreto têxtil, textile reinforced concrete (TRC), têxtil de vidro AR.

\section{INTRODUÇÃO}

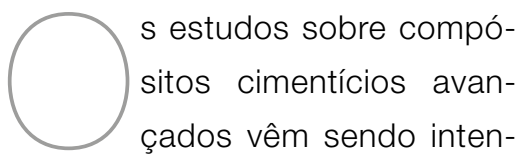

sificados nas últimas décadas, como
O concreto têxtil. O emprego dessa tecnologia visa substituir as barras convencionais de aço utilizadas como reforço em estruturas de concreto armado, pela inserção de fibras
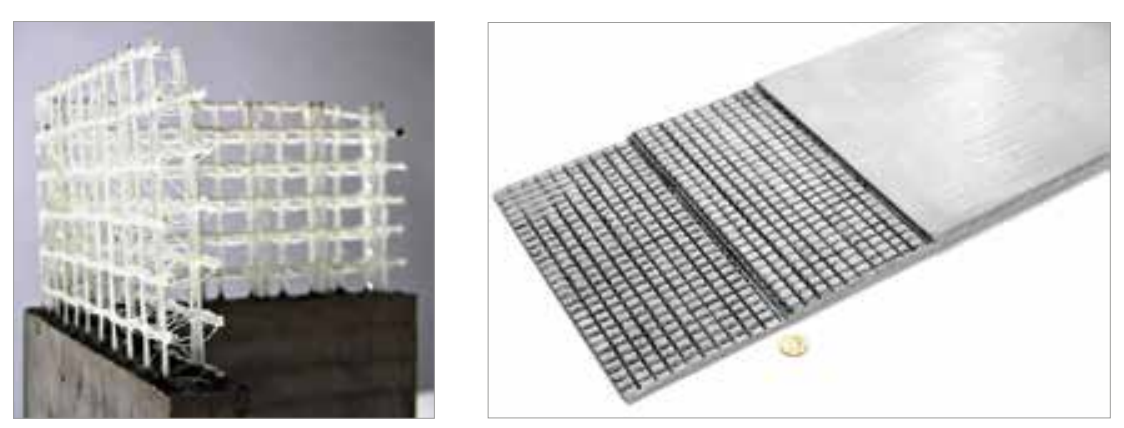

Figura 1

Configuração do concreto têxtil

Fonte: www.bft-international.com

contínuas bidirecionais distribuídas em forma de malhas.

Este trabalho mostra o comportamento mecânico do reforço têxtil de vidro AR produzido no Brasil, enfatizando especificamente a inserção de reforço têxtil produzido nacionalmente em uma matriz cimentícia, objetivando uma contribuição para viabilizar materiais nacionais e diminuir custo da tecnologia.

\section{CONCEITUAÇÃO DO CONCRETO TÊXTIL}

O Textile Reinforced Concrete (TRC) é constituído por pasta cimentícia, agregados miúdos, adições minerais e reforços com fibras longas bidirecionais (Figura 1). 


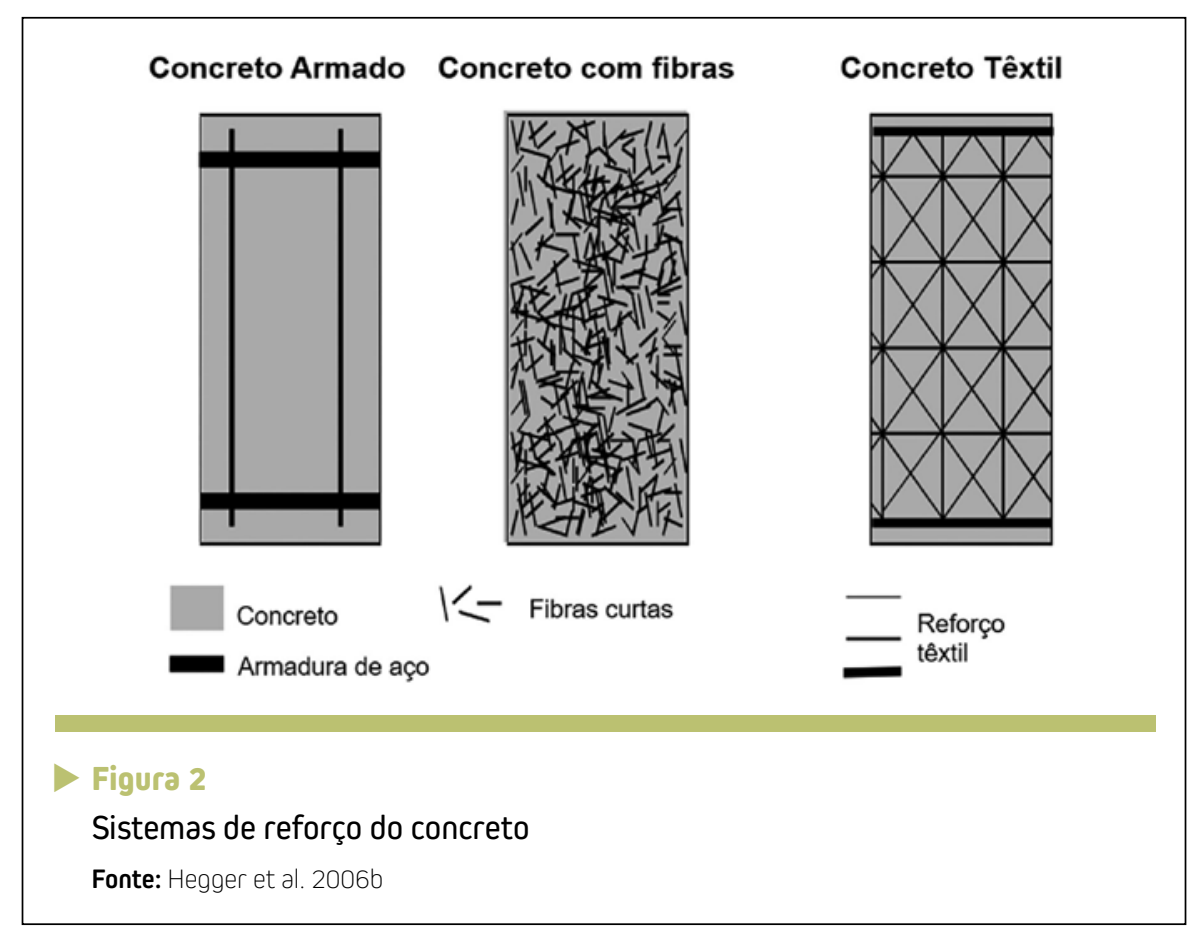

As propriedades mecânicas do TRC são consequência do alinhamento do reforço têxtil, orientado na direção dos esforços principais, que garante características diferentes aos concretos reforçados com as fibras descontínuas, dispersas na matriz.

A Figura 2 apresenta a diferença entre o concreto armado, o concreto com fibras curtas dispersas e o concreto têxtil.

Os têxteis podem ser produzidos por fibras de vidro álcali-resistente $(A R)$, carbono ou basalto. Em geral, a fibra de carbono possui o melhor desempenho quando comparada às de vidro $A R$ e basalto, devido à maior resistência à tração, quase três vezes maior que a do vidro AR. Em contrapartida, a fibra de vidro AR apresenta custo inferior do que a de carbono (PELED, 2018).

Para que as propriedades mecânicas do TRC sejam alcançadas de pode ser dividido em três estágios, com resistência à compressão superior a $40 \mathrm{MPa}$ deve interagir com o reforço têxtil. Quando o compósito é solicitado ao esforço de tração direta, Yao et al., (2015) reportam que o TRC apresenta comportamento que como ilustrado no diagrama tensão x deformação sobre carregamento uniaxial na Figura 3.

O estágio I caracteriza o elemento não fissurado, que corresponde ao módulo de elasticidade da matriz cimentícia. Neste estágio, apenas a matriz está sendo solicitada, ao passo que, a partir da primeira fissura, as fibras tornam-se efetivamente solicitadas. (PELED, 2016). O estágio Il começa com o início da primeira fissura e a propagação em toda a largura da amostra, que ocorre perpendicularmente ao menor lado do elemento.

Ao ingressar no estágio $\mathrm{Il}$, a rigidez do compósito diminui gradativamente, devido à formação de fissuras espaçadas regularmente. Conforme Hegger et al. (2006a), o espaçamento das fissuras é determinado pelo reforço e suas características de ligação ao concreto. Mesmo com a propagação das fissuras ao longo do corpo de prova,

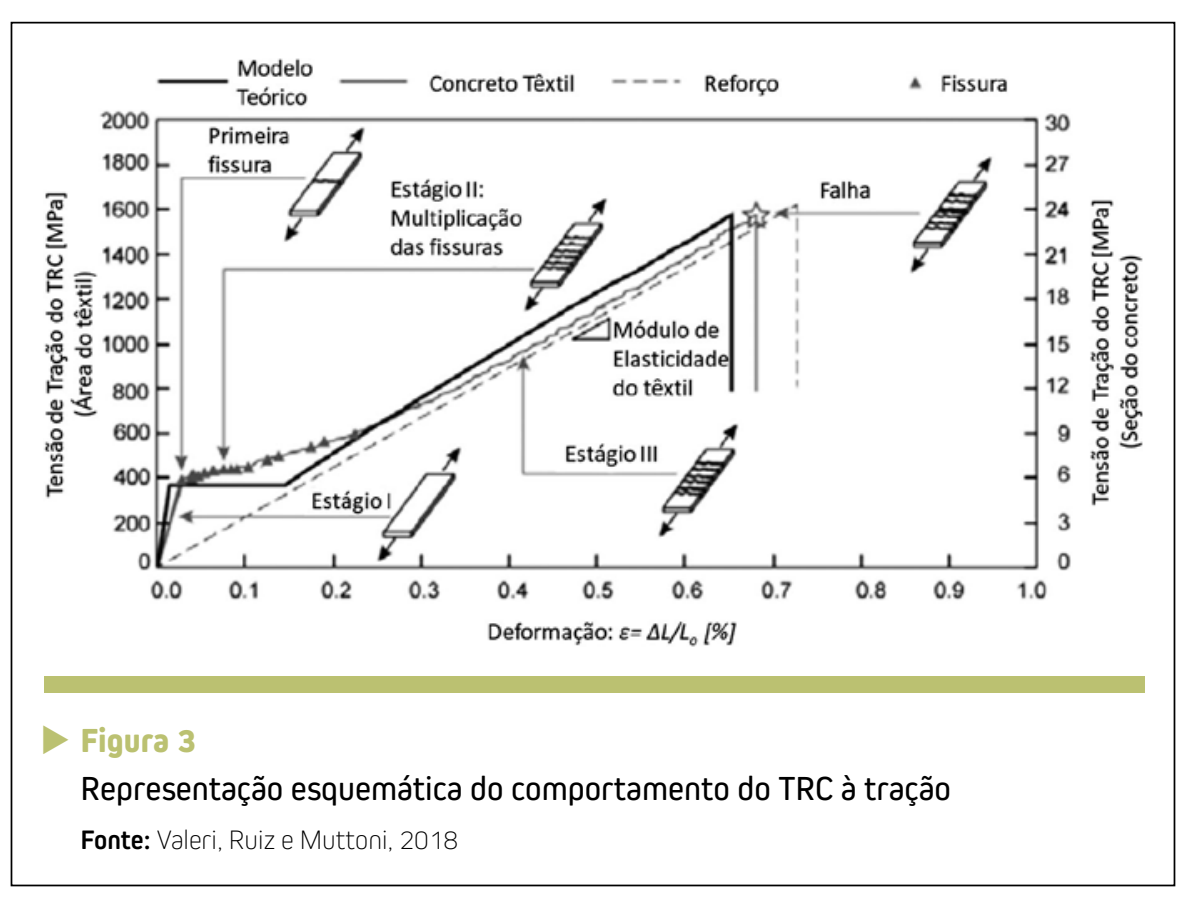




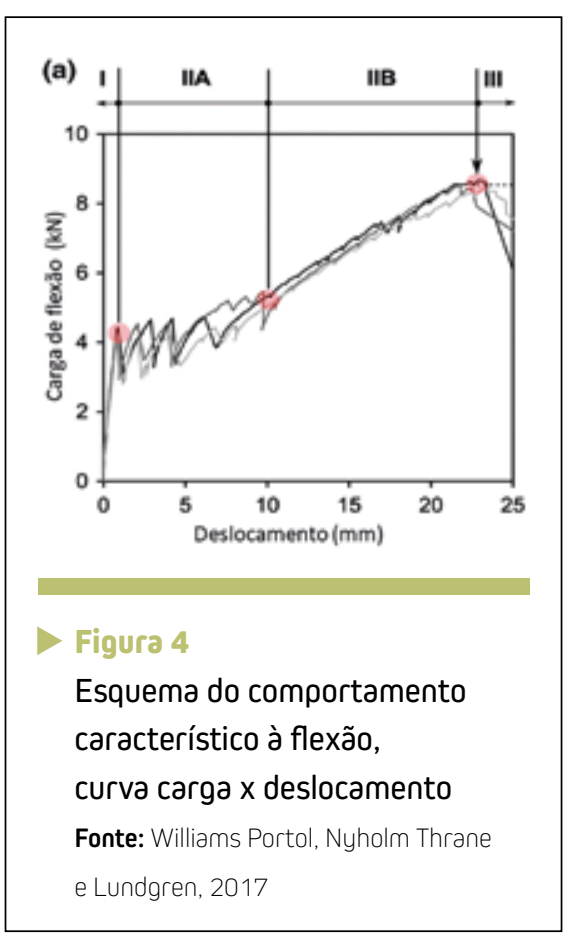

a capacidade de carga do composto fissurado continua aumentando, resultando no início do estágio III. Neste, já não há mais ocorrência de mais fissuras, apenas o reforço é solicitado. Este comportamento é atribuído à resistência e ao módulo de elasticidade do reforço têxtil. Assim, a falha sucede quando se atinge a tensão de ruptura do reforço, caracterizada como resistência máxima (pico) do compósito cimentício reforçado com têxtil. (HEGGER et al., 2006b)

$\mathrm{Na}$ situação em que o TRC é solicitado à flexão, cenário que caracteriza o comportamento em uso, visto que simula as condições reais aproximadas do concreto têxtil, as reações de compressão da matriz e tração do reforço atuam em ação conjunta frente às solicitações de flexão. Mobasher (2016) e Peled, Bentur e Mobasher (2017) argumentam que, como a resistência à com- pressão da matriz é superior ao de tração, a maior exigência do TRC é guiada pela zona tracionada. A relação carga $x$ deslocamento da solicitação de flexão pode ser dividida em três estágios, como ilustra a Figura 4.

No estágio I, há influência do regime elástico do material, não há surgimento de fissuras nesta região e o concreto permanece suportando os esforços. No estágio II, existe ocorrência de fissuras, com avanço da carga com o deslocamento. No estágio IIA há multiplicação das fissuras e no IIB não há surgimento de novas fissuras, apenas aumento da abertura das existentes, consecutivamente a carga é transferida diretamente para o tecido. A falha do sistema principia com o estágio III. Nesta etapa, há falha da aderência das fibras no concreto, ocorre a redução acentuada da carga, que pode ser atribuída ao escorregamento dos filamentos externos do fio. O sistema rompe quando há deslizamento dos filamentos do núcleo, desenvolven- do, assim, rompimento das fibras em forma telescópica - este modo de falha acontece lentamente por altas deformações.

As propriedades do material compósito de concreto reforçado com têxtil são influenciadas pelas propriedades do fio, assim como o material do fio e sua geometria, além da matriz, como tratado a seguir.

\section{PARTE EXPERIMENTAL}

A caracterização do comportamento mecânico de têxtil de vidro $A R$, produzido no Brasil, como reforço em matriz cimentícia, foi analisado de forma experimental com idade de cura da matriz em 28 dias, com solicitação à tração direta e à flexão.

Para isso, utilizou-se o tecido cujas informações estão apresentadas no Quadro 1, revestido com resina acrílica sem função estrutural, apenas para agrupar os filamentos.

Adotou-se para o estudo mistura do concreto com o traço 1:2,1 (cimento:areia), com adição de 10\%

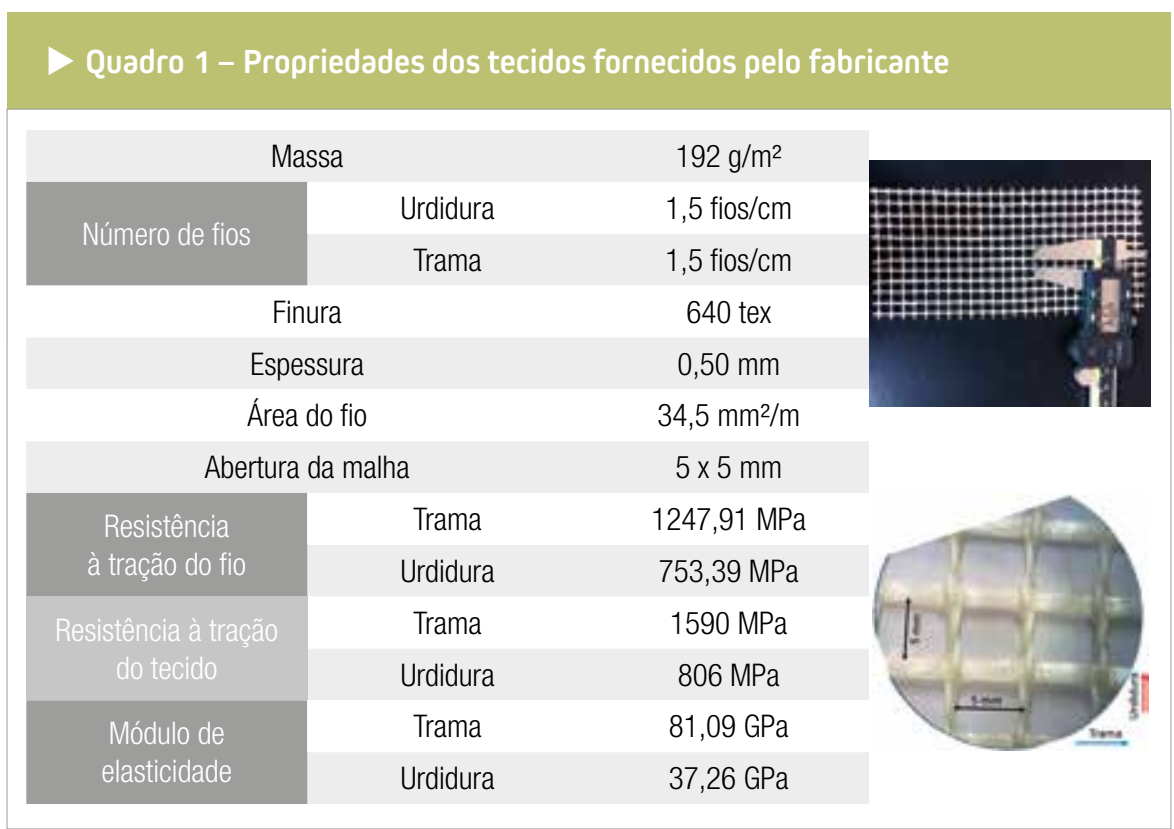




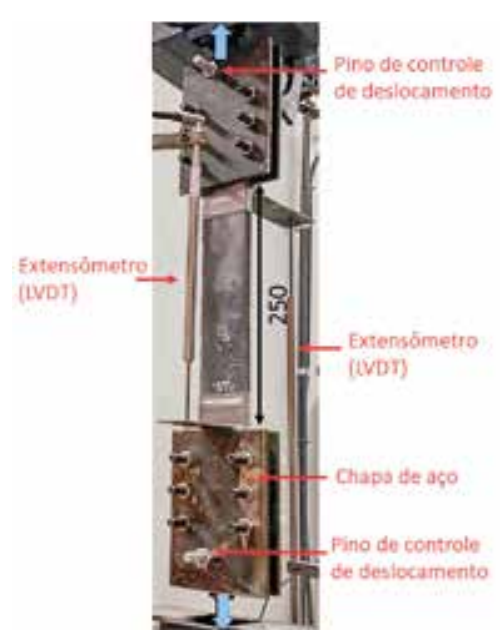

(a)

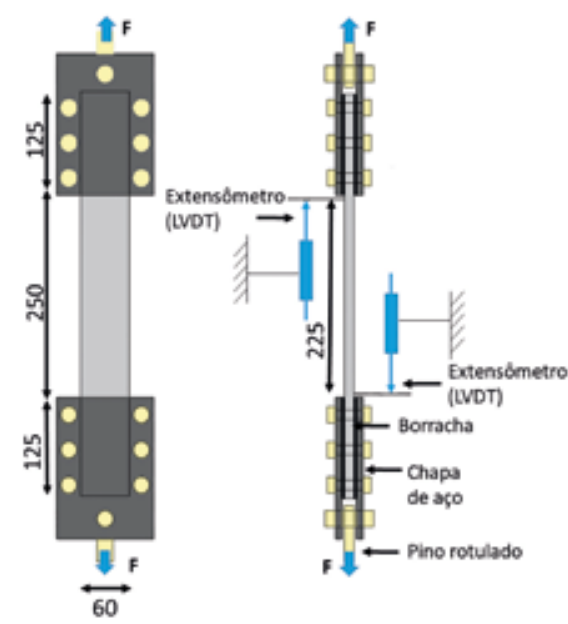

(b)

\section{Figura 5}

Configuração do ensaio de tração direta, unidade em mm

Fonte: RILEM, 2016

de sílica ativa em relação à massa de cimento, com relação água/aglomerante de 0,4, e com resistência à compressão potencial aos 28 dias de 60,3 MPa e módulo de elasticidade de 33,4 GPa.

Para caracterização mecânica

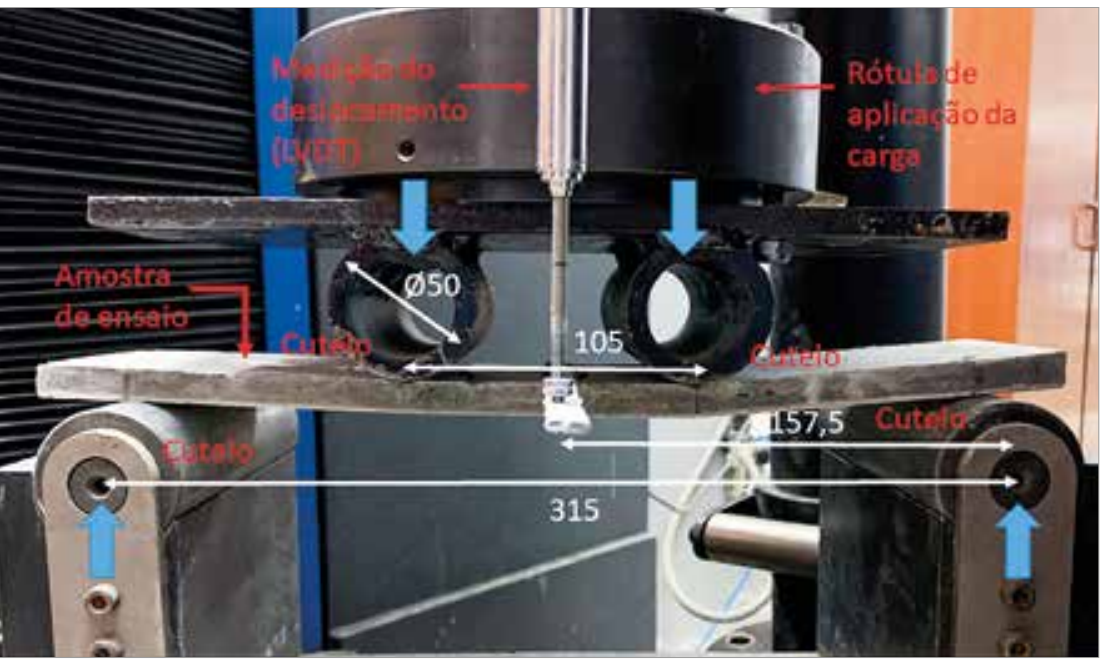

Figura 6

Configuração do ensaio de flexão, unidades em mm

Fonte: Autor, 2020 dos corpos de prova em milímetros. A espessura das amostras foi de $12 \mathrm{~mm}$. A leitura das deformações foi feita por dois extensômetros, posicionados em ambas as faces da peça de concreto têxtil.

O ensaio de tração foi realizado com taxa de deformação de $0,2 \% / m i n$, sendo o comprimento de $500 \mathrm{~mm}$ do corpo de prova, corresponde a uma taxa de deslocamento vertical da máquina de ensaio de 1 $\mathrm{mm} / \mathrm{min}$. O ensaio foi conduzido até a ruptura do corpo de prova.

O ensaio foi realizado pelo método dos 4 pontos, como sugerido por Vlach et al. (2018) e Hawkins et al. (2018), com procedimento especificado pela norma ASTM C947-3:2016, com taxa de carregamento controlada de 2,0 $\mathrm{mm} / \mathrm{min}$, sendo este deslocamento do equipamento, e não da amostra. O deslocamento da amostra foi registrado com auxílio de um extensômetro do tipo LVDT, posicionado no centro da amostra, como apresenta o esquema na Figura 6.

O ensaio de resistência à flexão foi conduzido em corpos de prova, com dimensões recomendadas por Vlach

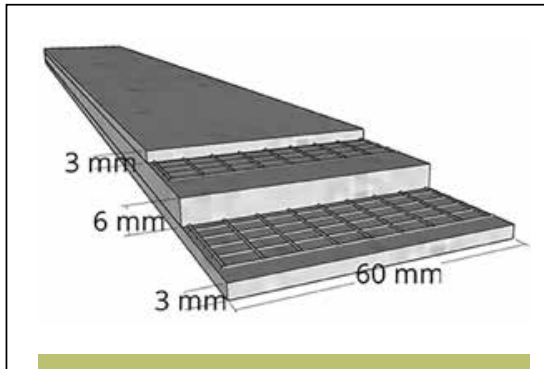

Figura 7

Esquema e posicionamento do reforço para ensaio de tração direta

Fonte: Autor, 2020 
et al. (2018), sendo $100 \mathrm{~mm}$ de largura, $360 \mathrm{~mm}$ de comprimento e $12 \mathrm{~mm}$ de espessura.
Os valores de carga, tensão, deslocamento e deformação foram registrados a cada 0,1 segundo.

Tabela 1 - Tensões e deformações das amostras de concreto têxtil à tração

\begin{tabular}{ccccc} 
Amostra & $\begin{array}{c}\text { Tensão na } \\
1^{\mathrm{a}} \text { físsura } \\
\sigma_{\text {or }}(\mathrm{MPa})\end{array}$ & $\begin{array}{c}\text { Deformação na } \\
1^{\mathrm{a}} \text { fissura } \\
\varepsilon_{\text {or }}(\%)\end{array}$ & $\begin{array}{c}\text { Tensão máxima } \\
\sigma_{\max }(\mathrm{M} / \mathrm{Pa})\end{array}$ & $\begin{array}{c}\text { Deformação na } \\
\text { tensão máxima } \\
\varepsilon_{\text {or }}(\%)\end{array}$ \\
\hline A & 2,95 & 0,238 & 5,79 & 4,30 \\
B & 3,23 & 0,500 & 5,63 & 2,74 \\
C & 3,20 & 0,894 & 6,59 & 2,89 \\
Média & 3,13 & 0,544 & 6,00 & 3,31 \\
\hline
\end{tabular}

Tabela 2 - Força e deslocamento das amostras de concreto têxtil à flexão

\begin{tabular}{|ccccc} 
Amostra & $\begin{array}{c}\text { Força na } \\
1^{\text {a }} \text { fissura }(\mathrm{N})\end{array}$ & $\begin{array}{r}\text { Deslocamento } \\
\text { na } 1^{\mathrm{a}} \text { fissura } \\
(\mathrm{mm})\end{array}$ & $\begin{array}{c}\text { Força máxima } \\
(\mathrm{N})\end{array}$ & $\begin{array}{c}\text { Deslocamento } \\
\text { na força } \\
\text { máxima (mm) }\end{array}$ \\
\hline A & 306,0 & 1,195 & 813,9 & 25,544 \\
B & 380,6 & 0,509 & 822,2 & 23,621 \\
C & 212,3 & 0,288 & 724,5 & 27,119 \\
Média & 299,6 & 0,664 & 786,8 & 25,428 \\
\hline
\end{tabular}

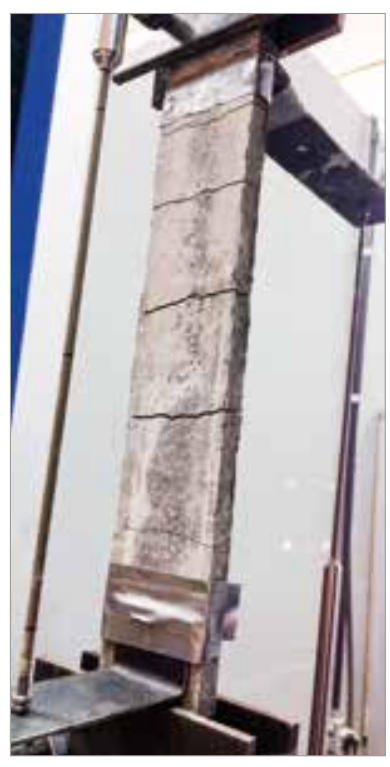

(a)
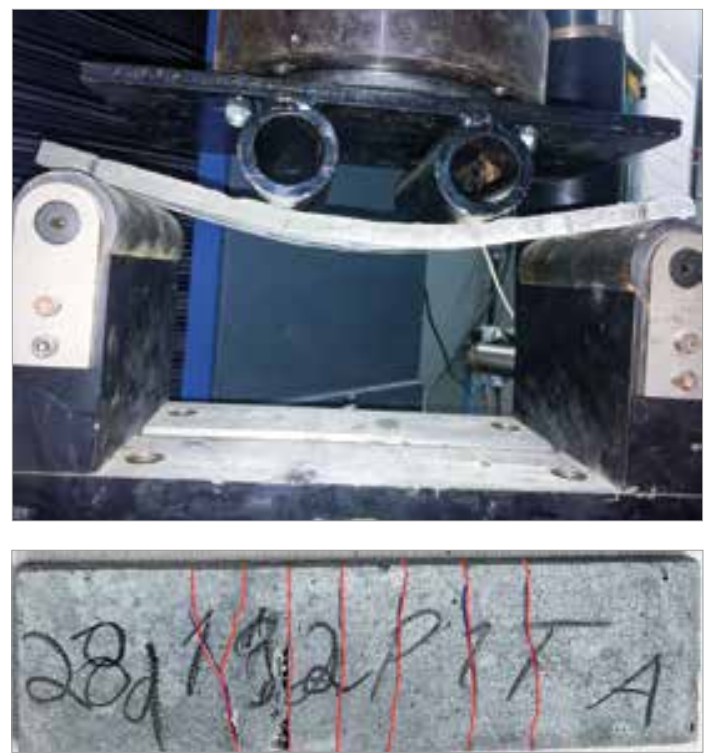

(b)

Figura 8

Aspecto final dos corpos de prova após ensaio, (a) tração (b) flexão Fonte: Autor, 2020

Durante o ensaio, foram registrados os momentos. As resistências à tração direta e à flexão foram determinadas a partir de três corpos de prova. Foram posicionadas duas camadas de reforço têxtil de fibra de vidro $A R$, com cobrimento de 3 $\mathrm{mm}$ em cada face, como ilustra a Figura 7, com o têxtil orientado na direção da urdidura.

Para análise dos parâmetros de dimensionamento analítico, tomou-se como base apenas a orientação do têxtil na direção da trama, uma vez que apresentou comportamento mecânico, quando isolado, superior à orientação da urdidura, no que tange à resistência à tração e ao módulo de elasticidade. Além do mais, o módulo de elasticidade do fio na orientação da urdidura apresentou valor próximo ao módulo de elasticidade da matriz cimentícia, que pode não ser indicado como elemento de reforço estrutural (PELED, 2018).

\section{RESULTADOS}

Os resultados dos ensaios de tração e flexão dos corpos de prova reforçados com o têxtil são apresentados, respectivamente, na Tabela 1 e Tabela 2.

Os resultados apresentados evidenciam uma evolução da resistência com deformação entre a primeira fissura e a máxima, visto que, com a resistência média e individual, de ambos os ensaios, há aumento da resistência máxima em relação ao valor necessário para formar a primeira fissura. 0 mesmo ocorre com a deformação: há avanço da deformação com o crescimento da resistência. 


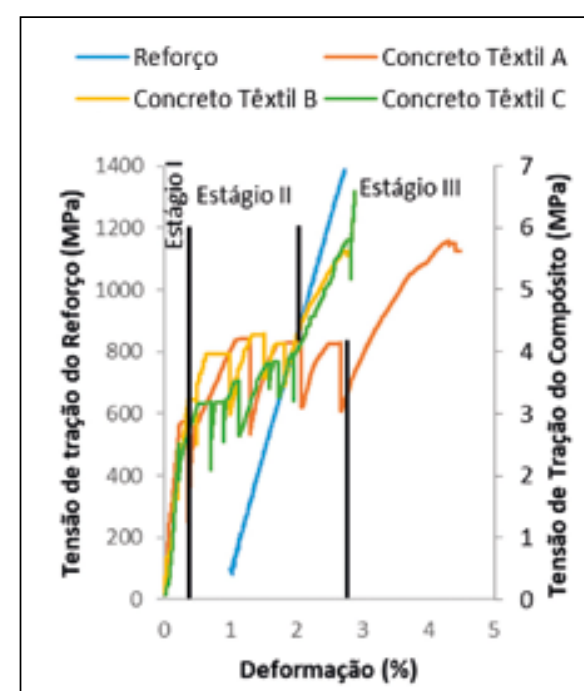

(a)

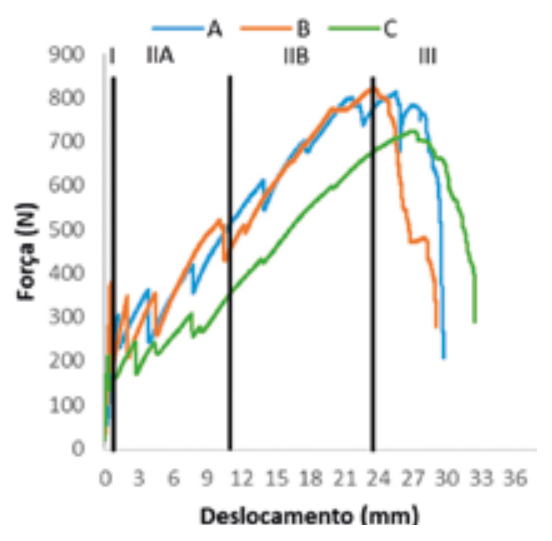

(b)

\section{Figura 9}

Identificação das zonas constitutivas do concreto têxtil, (a) tração do compósito e do reforço; (b) flexão do compósito

O aspecto final das amostras ensaiadas à tração e à flexão, é apresentado na Figura 8. Percebeu-se formação visível de um padrão de fissuração espaçadas com aproximada regularidade.

Percebe-se que o compósito reforçado com o têxtil produzido no Brasil apresentou ganhos de resistência à tração direta e há ancoragem do têxtil à matriz. Isto é evidenciado pelo aumento do número de fissuras e pela progresso das deformações e deslocamento com ganhos da resistência.

A Figura 9 relaciona o comportamento encontrado nas amostras ensaiadas, nos distintos procedimentos de ensaio, com a lei constitutiva do concreto têxtil, conforme os diferentes estágios apontados por Valeri, Ruiz e Muttoni (2018) e Williams Portal, Nyholm Thrane e Lundgren (2017), respectivamente ao compor- tamento à tração (Figura 9a) e à flexão (Figura 9b).

O comportamento mecânico das amostras com duas camadas de reforço apresenta semelhança com a configuração desejada para concreto têxtil, uma vez que há ocorrências dos três estágios distintos de atuação, quando solicitado ao esforço de tração direta e flexão (PELED; BENTUR; MOBASHER, 2017).

É possível destacar semelhança no comportamento das amostras solicitadas à tração de TRC, ao Iongo do estágio III, com o tecido puro. Visto que ocorre atuação em paralelo da tensão versus deformação, pois, durante este estágio, apenas o reforço é solicitado, o que indica conformidade com comportamento do reforço isolado.

Além do mais, os compósitos reforçados com duas camadas de têxtil AR192, na direção da trama, pode ser caracterizado com as propriedades que qualificam o reforço com comportamento de concreto têxtil, dado que os corpos de prova apresentam crescimento da resistência após o surgimento da primeira fissura, manifestação de múltiplas fissuras e redução gradativa da carga depois de alcançar a força máxima.

Pode-se ainda observar a configuração de ruptura do reforço quando o compósito é solicitado à tração direta, conforme padrão de ruptura do tipo telescópio, apresentado na Figura 10 com ampliação de 50x.

A ruptura dos filamentos ocorre com falha precoce dos filamentos externos ligados diretamente com a matriz, com solicitação residual dos filamentos internos, que escorregam, menos aderidos com a matriz, e configuram, de modo análogo, uma ruptura do tipo telescópio.

\section{CONCLUSÃO}

Através dos ensaios, foram

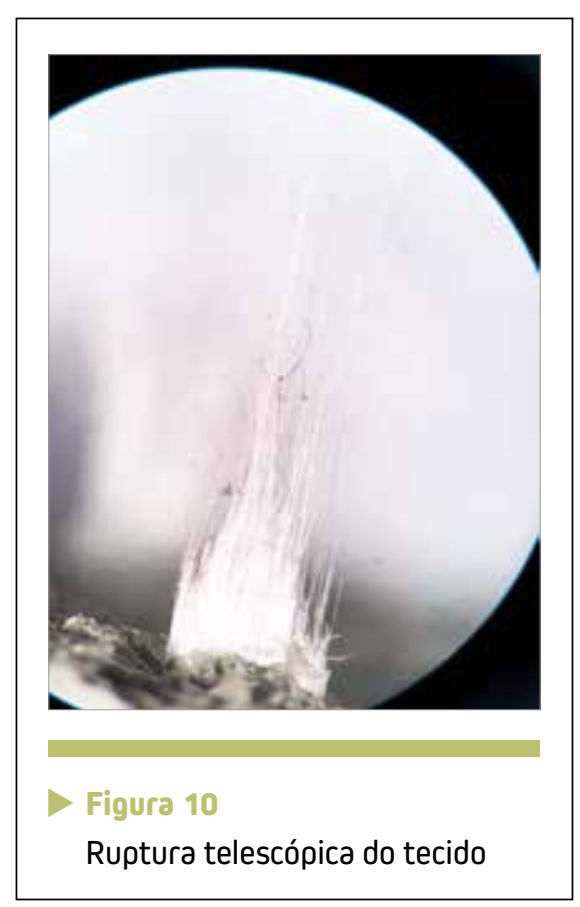


observadas propriedades importantes da atuação no conjunto do reforço têxtil de fibra de vidro AR, como reforço em matriz cimentícia, quando esse é solicitado à flexão e à tração, que se assemelham ao comportamento desejado de elementos em concreto têxtil.

Sendo possível destacar a atuação nos diferentes estágios cons- titutivos do TRC, com distinção da fase elástica da matriz, seguido pelo instante do surgimento da primeira fissura e formação de múltiplas fissuras, até a fase em que o reforço é solicitado isolado, atingindo o ponto de carga máxima, com posterior ruptura do compósito.

Em ambas as análises mecânicas, há crescimento da resistência com avanço da deformação, sendo que a resistência máxima é superior à resistência de fissuração.

Os resultados são promissores quanto ao uso de concreto reforçado com têxtil produzido no Brasil. Entretanto, pesquisas adicionais são necessárias para maior desempenho das resistências para o emprego corrente da tecnologia.

\section{> REFERENCIAS BIBLIOGRÁFICAS}

[1] ASTM C947-03 - Standard Test Method for Flexural Properties of Thin-Section Glass-Fiber-Reinforced Concrete (Using Simple Beam With Third-Point Loading), 2017.

[2] HAWKINS, W. et al. An Analytical Failure Envelope for the Design of Textile Reinforced Concrete Shells. Structures, v. 15, n. June, p. 56-65, 2018.

[3] HEGGER, J.; VOSS, S. Textile reinforced concrete under biaxial loading. 6th Rilem Symposium on Fiber Reinforced Concrete (FRC), BEFIB 2004, n. September, p. 1463-1472, 2004

[4] HEGGER, J. et al. Load-bearing behaviour and simulation of textile reinforced concrete. Materials and Structures/Materiaux et Constructions, v. 39, n. 292, p. 765-776, 2006a.

[5] HEGGER, J. et al. Mechanical behaviour of textile reinforced concrete. State-of-the-Art Report of RILEM Technical Committee 201-TRC: Textile Reinforced Concrete, p. 133-183, 2006b.

[6] PELED, A. Bonds in textile reinforced concrete composites. In: TRIANTAFILLOU, T. C. (Ed.). . Textile Fibre Composites in Civil Engineering. 2016. p. 63-99.

[7] PELED, A.; MOBASHER, B.; BENTUR, A. Durability of TRC. In: Textile Reinforced Concrete. 2017. p. 365-421.

[8] PELED, A. Material Design of TRC and TRC Impact Resistance. In: RILEM Bookseries -Strain-Hardening Cement-Based Composites. 2018. p. 351-358.

[8] RILEM TECHNICAL COMMITTEE 232-TDT. Recommendation of RILEM TC 232-TDT: test methods and design of textile reinforced concrete: Uniaxial tensile test: test method to determine the load bearing behavior of tensile specimens made of textile reinforced concrete. Materials and Structures, v. 49, p. 4923-4927, 2016.

[9] VALERI, P.; RUIZ, M. F.; MUTTONI, A. Experimental research on Textile Reinforced Concrete for the development of design tools. p. 1-8, 2018.

[10] VLACH, T. et al. Soft Insert for Support Modeling of Slightly Textile Reinforced Concrete. Key Engineering Materials, v. 760, p. 158-163, 2018.

[11] WILLIAMS PORTAL, N.; NYHOLM THRANE, L.; LUNDGREN, K. Flexural behaviour of textile reinforced concrete composites: experimental and numerical evaluation. Materials and Structures, v. 50, n. 1, p. 4, 2017.

[12] YAO, Y. et al. Tension stiffening in textile-reinforced concrete under high speed tensile loads. Cement and Concrete Composites, v. 64, p. 49-61, 2015.

[13] VALERI, P.; RUIZ, M. F.; MUTTONI, A. Experimental research on Textile Reinforced Concrete for the development of design tools. p. 1-8, 2018.

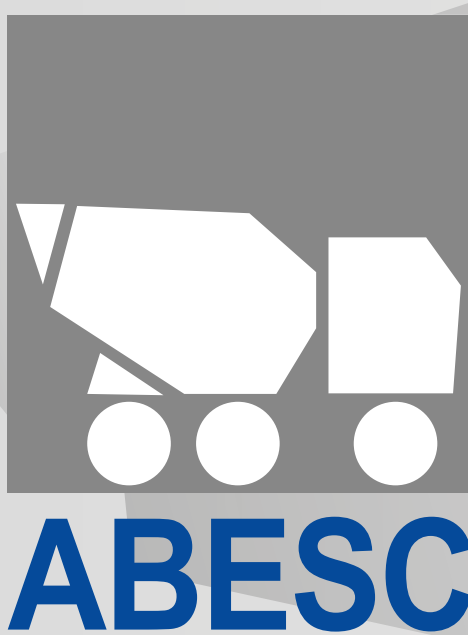

\section{AABESC parabeniza a Revista Concreto \& Construções} por sua centésima edição e por sua enorme contribuição para o desenvolvimento da 